\title{
Vitamin B12 and homocysteine levels in blood of dairy cows during subacute ruminal acidosis
}

Chiara Cannizzo', Matteo Gianesella', Stefania Casella², Elisabetta Giudice ${ }^{3}$, Annalisa Stefani ${ }^{4}$, Luigi Michele Coppola ${ }^{1}$ and Massimo Morgante ${ }^{1}$

'Dipartimento di Scienze Cliniche Veterinarie, Facoltà di Medicina Veterinaria, Università degli Studi di Padova, Legnaro, Italy, ${ }^{2}$ Dipartimento di Scienze Sperimentale e Biotecnologie Applicate, Facoltà di Medicina Veterinaria, Università degli Studi di Messina, Messina, Italy, ${ }^{3}$ Dipartimento di Sanità Pubblica Veterinaria, Facoltà di Medicina Veterinaria, Università degli Studi di Messina, Messina, Italy, ${ }^{4}$ Istituto Zooprofilattico Sperimentale delle Venezie, Legnaro, Italy

\begin{abstract}
The aim of this study was to investigate the variations of vitamin B12 and homocysteine in blood of dairy cows during subacute ruminal acidosis (SARA). On 228 subjects ruminal liquid was collected through rumenocentesis technique and rumen $\mathrm{pH}$ was immediately measured by a portable $\mathrm{pH}$-meter. On the basis of $\mathrm{pH}$ values all cows were classified (bovine class) in Group A (animals with rumen $\mathrm{pH}>5.7$ ), Group B (animals with rumen $\mathrm{pH}$ between 5.6 and 5.7) and Group $\mathrm{C}$ (animals with rumen $\mathrm{pH}<5.6$ ). In relation to the acidosis risk depending on the rumen $\mathrm{pH}$ (herd class), the herds were classified in Group 1 (normal herds: less than $33 \%$ cows with rumen $\mathrm{pH}<5.8$ ), Group 2 (critical herds: more than $33 \%$ cows with rumen $\mathrm{pH}$ between 5.5 and 5.8) and Group 3 (acidosis herds: more than $33 \%$ cows with rumen $\mathrm{pH}<5.5$ ). On blood samples, collected by jugular venipuncture, vitamin B12 and homocysteine were measured by chemiluminescent immunological tests. One-way analysis of variance (ANOVA), followed by Bonferroni test, showed significant differences $(P<0.05)$ for vitamin B12 in bovine class and significant differences $(P<0.05)$ for homocysteine in herd class. The influence of rumen $\mathrm{pH}$ values resulted in adequate vitamin $\mathrm{B} 12$ and homocysteine levels to meet microbial and cow requirements and fatty acids modifications in dairy cows affected by SARA. Moreover, the increase of vitamin B12 could be due to the presence of analogues which interfere with the transport of the vitamin. These findings provide more information on blood modifications during SARA.
\end{abstract}

Keywords: dairy cows, dairy herds, homocysteine, rumen $\mathrm{pH}$, subacute ruminal acidosis, vitamin B12

\section{Introduction}

Subacute ruminal acidosis (SARA) is though to be a common condition in early lactating dairy cows. It is a common and serious health and production problem in dairy cows and herds (Nordlund 1996, Oetzel 2003). The determination of rumen $\mathrm{pH}$ is a key factor for the diagnosis of SARA (Morgante et al. 2007, Gianesella et al. 2010). Rumen pH values lower than 5.6 are considered abnormal and suggestive of either severe SARA, or possibly in combination with clinical signs, whereas rumen $\mathrm{pH}$ values of 5.6 to 5.8 are considered marginal and values of 
rumen pH higher than 5.8 are normal (Nordlund \& Garrett 1994). Generally spoken, SARA therefore has to be defined as an intermittent fall of rumen $\mathrm{pH}$ to non-physiological levels after uptake of a certain concentrate based diet because of a non-adaption of the ruminal environment in terms of flora and ruminal mucosa (Kleen et al. 2003). In fact, among its numerous manifestations, SARA impairs the activity of ruminal cellulolytic bacteria (Grant \& Mertens 1992) and various reports have demonstrated a decreased fibre digestion both in vitro (Calsamiglia et al. 2002) and in vivo (Plaizier et al. 2001, Krajcarski-Hunt et al. 2002) under SARA conditions in dairy cows. In addition, a lower ratio of forage to concentrate in the diet is known to reduce ruminal synthesis of vitamin B12 (Kincaid \& Socha 2007, Tiffany et al. 2006). This vitamin, also called cobalamin, is synthesised by the intestinal microflora in nonruminant species and by rumen microbes in ruminants. Its synthesis is influenced by many factors such as the cobalt availability and the rumen $\mathrm{pH}$ since an acidic environment may cause lysis of B12 synthesising bacteria. Several studies have demonstrated that vitamin B12 is an important growth factor for some ruminal microorganisms (Tanner \& Wolfe 1988, Strobel 1992) and is utilised by others in pathways that produce propionate (Chen \& Wolin 1981). After several transformations in the body, cobalamin as a cofactor is used in several reactions important to the citric acid cycle and gluconeogenesis. It is involved in metabolism of odd numbered fatty acid like propionate and in biosynthesis of methionine from homocysteine. This, a sulphur intermediate amino acid in the metabolism of methioninecysteine, may undergo remethylation to methionine in a pathway dependent on vitamins B12 (via methionine synthase) and folate (via contribution of a substrate to the remethylation cycle) (Welch \& Loscalzo 1998, Finkelstein \& Martin 2000). Several studies have shown that plasma homocysteine levels are affected by diet factors such as protein and vitamin deficiencies (Kalantar-Zadeh et al. 2003, Yeh \& Yeh 2006), by genetic background and by several pathological conditions (Ridker 1997, den Heijer 1996, Ray 1998, Langman 2000). Moreover, the hyperhomocysteinemia was also associated with chronic inflammatory bowel disease (Roblin 2005) and with vitamin B12 low levels (Romagnuolo et al. 2001).

The aim of this study was to investigate the variations of vitamin B12 and homocysteine in blood of multiparous Holstein dairy cows during SARA.

\section{Materials and methods}

The study, conducted from June to October 2010 in 21 intensive Italian dairy herds, located in North Italy, was carried out on 228 multiparous Holstein dairy cows. As far as surveyings on the single animals, for every herd we chose 10 or 11 bovine, a statistically significance number inside of the herd (Nordlund \& Garrett 1994, Nordlund 2001, Kleen et al. 2003). All housing and care conditions were conformed to the standards recommended by the Guide for the Care and Use of Laboratory Animals, Directive 2010/63/EU and Directive 1998/58/EU.

All cows were between 7 and 90 days in milk (DIM) and all dairy herds had a high average farm milk production (about $10000 \mathrm{~kg}$ per year). Cows were housed in free stalls, fed a total mixed ration, and had received a steam-up diet in the final part of the dry period. Feed were analysed by near infrared spectroscopy (NIRS) using NIRS 5000 (Foss, Hillerød, Denmark) and an in-house calibration. Table 1 shows the chemical composition of diets consumed by dairy cows during steaming-up and subsequent early lactation. The value of neutral detergent 
fibre, acid detergent fibre, non fibre carbohydrates, starch and crude protein, are the same in all herds, with values within the normal range for each period and this chemical composition represent the normal condition in Italian dairy herds.

Table 1

Mean chemical composition of total mixed rations fed to dairy cows during steaming-up and early lactation

\begin{tabular}{lcc}
\hline Chemical composition of diet in dry matter, \% & Steaming-up & Early lactation \\
\hline Crude protein & 13.37 & 16.59 \\
Ethreal extract & 4.30 & 6.01 \\
Ash & 7.38 & 7.42 \\
Neutral detergent fibre & 40.77 & 30.17 \\
Non fibre carbohydrates & 34.17 & 38.81 \\
Dry matter degradable & 59.02 & 68.48 \\
Acid detergent fibre & 24.82 & 20.37 \\
Starch & 14.74 & 28.46 \\
Dietary cation-anion balance & 35.49 & 49.39 \\
\hline
\end{tabular}

On all subjects rumen fluid was collected by rumenocentesis as previously described by Morgante et al. (2007), without sedation, using a 13 gauge $105 \mathrm{~mm}$ needle. The sampling time was between 4 and $6 \mathrm{~h}$ post total mixed ration distribution as recommended previously. Rumen $\mathrm{pH}$ was immediately determined after sampling using a portable $\mathrm{pH}$ meter (Piccolo, Hanna Instruments, Leighton Buzzard, UK). On the basis of $\mathrm{pH}$ values obtained all subjects were classified (bovine class) into three different Groups: Group A (animals with rumen $\mathrm{pH}>5.7$ ), Group B (animals with rumen pH between 5.6 and 5.7) and Group C (animals with rumen $\mathrm{pH}<5.6)$. In addition, using the classification scheme proposed by Nordlund \& Garrett (1994), the herds were classified, in relation to the acidosis risk depending on the rumen $\mathrm{pH}$ (herd class in Group 1 (normal herds: less than $33 \%$ cows with rumen $\mathrm{pH}<5.8$ ), Group 2 (critical herds: more than $33 \%$ cows with rumen pH between 5.5 and 5.8) and Group 3 (acidosis herds: more than $33 \%$ cows with rumen $\mathrm{pH}<5.5$ ).

All Groups showed a similar body condition score and average values were $3.59 \pm 0.23$, in a 1 to 5 scale, according the procedure of Edmonson et al. (1989). On all animals blood samples were collected by jugular venipuncture, under aseptic conditions, and included into tubes containing $1.2 \mathrm{mg}$ of anhydrous salt of ethylenediaminetetraacetic acid (EDTA) per $\mathrm{ml}$ of blood. The determination of vitamin B12 was performed with a solid phase, competitive chemilumiscent enzyme immunoassay (Immulite 1000 Vitamin B12, Medical System s.p.a., Genoa, Italy) by means of immunoassay automated system (Immulite One, Medical System s.p.a., Genoa, Italy). Plasma total homocysteine was measured by a competitive chemiluminescent immunological test again (Immulite Homocysteine, Medical System s.p.a., Genoa, Italy) by means of the same analyser Immuilte One. One-way analysis of variance (ANOVA) was applied to compare the Groups A, B and C in bovine class and one-way ANOVA was applied to compare the Groups in herd class (Groups 1, 2 and 3). Bonferroni's test was applied for post hoc comparison. A $P$-value $<0.05$ was considered statistically significant. All data were analysed using Statistica 7 (StatSoft Inc, Tulsa, OK, USA). 


\section{Results}

The average values of rumen $\mathrm{pH}$, vitamin $\mathrm{B} 12$ and homocysteine, together with their standard deviation of the means (SD) and statistical significances, in dairy cows of Groups A, B and C are presented in Table 2. Instead, the mean values $( \pm S D)$ of the parameters studied, together with statistical significances, in dairy herds of Groups 1, 2 and 3 are presented in Table 3.

Table 2

Average values $( \pm S D)$ of rumen $\mathrm{pH}$, homocysteine and vitamin $\mathrm{B} 12$, together with the relative statistical significances in experimental groups

\begin{tabular}{|c|c|c|c|}
\hline \multirow[t]{2}{*}{ Parameters } & \multicolumn{3}{|c|}{ Experimental groups (Bovine class) } \\
\hline & Group A $(n=155)$ & Group B $(n=49)$ & Group C ( $n=24)$ \\
\hline Rumen $\mathrm{pH}$ & $6.17 \pm 0.29$ & $5.69 \pm 0.06^{*}$ & $5.45 \pm 0.14 *, * *$ \\
\hline Vitamin $B 12, \mathrm{pg} / \mathrm{mL}$ & $208.50 \pm 43.55$ & $210.20 \pm 41.86$ & $241.90 \pm 32.27^{*}, * *$ \\
\hline Homocysteine, $\mu \mathrm{mol} / \mathrm{L}$ & $4.18 \pm 0.97$ & $3.99 \pm 0.94$ & $3.77 \pm 0.81$ \\
\hline
\end{tabular}

Group A: animals with rumen $\mathrm{pH}>5.7$, Group B: animals with rumen $\mathrm{pH}$ between 5.6 and 5.7, Group C: animals with rumen $\mathrm{pH}<5.6,{ }^{*} P<0.01$ vs. Group $\mathrm{A},{ }^{*} P<0.05$ vs. Group $B$

Table 3

Average values $( \pm S D)$ of rumen $\mathrm{pH}$, homocysteine and vitamin $\mathrm{B} 12$, together with the relative statistical significances in experimental groups

\begin{tabular}{|c|c|c|c|}
\hline \multirow[t]{2}{*}{ Parameters } & \multicolumn{3}{|c|}{ Experimental groups (Herd class) } \\
\hline & Group $1(n=65)$ & Group $2(n=71)$ & Group 3 (n=92) \\
\hline Rumen $\mathrm{pH}$ & $6.16 \pm 0.37$ & $6.01 \pm 0.31$ & $5.85 \pm 0.34^{*}$, ** \\
\hline Vitamin B12, pg/mL & $206.30 \pm 41.94$ & $208.40 \pm 39.36$ & $219.50 \pm 46.20$ \\
\hline Homocysteine, $\mu \mathrm{mol} / \mathrm{L}$ & $4.57 \pm 1.09$ & $3.97 \pm 0.82^{*}$ & $3.85 \pm 0.85^{*}$ \\
\hline
\end{tabular}

Group 1: normal herds - less than $33 \%$ cows with rumen $\mathrm{pH}<5.8$ ), Group 2: critical herds - more than $33 \%$ cows with rumen $\mathrm{pH}$ between 5.5 and 5.8, Group 3: acidosis herds - more than $33 \%$ cows with rumen $\mathrm{pH}<5.5,{ }^{*} P<0.001$ vs. Group 1, ${ }^{* *} P<0.05$ vs. Group 2

The application of one-way ANOVA in bovine class showed a statistical significance on rumen $\mathrm{pH}\left(\mathrm{F}_{(2 ; 22)}=127.80 ; P<0.0001\right)$ and vitamin B12 $\left(\mathrm{F}_{(2,225)}=6.34 ; P=0.0029\right)$. Data elaboration no pointed out statistically significant differences for homocysteine.

One-way ANOVA in herd class showed a statistical significance on rumen $\mathrm{pH}\left(\mathrm{F}_{(2 ; 225)}=14.86\right.$; $P<0.0001)$ and homocysteine $\left(F_{(2,225)}=12.39 ; P<0.0001\right)$. Data elaboration no pointed out statistically significant differences for vitamin B12.

\section{Discussion}

The analysis of the results obtained in the present study indicated an increase of vitamin B12 values in dairy cows with lower rumen $\mathrm{pH}$ and a decrease of homocysteine values in dairy herds with lower rumen $\mathrm{pH}$.

Vitamin B12 concentration increased in animals with lower rumen $\mathrm{pH}$, with significant values only in dairy cows with rumen $\mathrm{pH}<5.6$, in fact in critical and acidosis herds vitamin B12 increased slightly. This significant increase obtained in Groups B and C vs. Group A could be explained considering the different microorganisms present in the rumen, their nutrient requirements and metabolism, what roles they play and how a perturbation or 
an imbalance in the microbial population may lead to several metabolic disorders which can have a direct impact on productivity and health. In fact, together with the decrease of rumen $\mathrm{pH}$ significant quantities of vitamin B12 are synthesised in the rumen since microbes, particularly sensible to variations of rumen fluid, produce vitamins required by the cow (NRC 2001). The rumen contains a complex and diverse array of anaerobic bacteria and fungi, and specialized protozoa that live only in the rumen and synthesise vitamin $\mathrm{K}$ and all $\mathrm{B}$ vitamins inside their cells. They in turn supply these vitamins to other rumen microbes and finally to the animal confirming that the vitamins are an important growth factor for ruminal microorganisms (NRC 2001). Rumen bacteria have their own requirements for some of the $B$ vitamins such as vitamin B12 that as demonstrated increased in our study. Moreover, as previously demonstrated (Schwab et al. 2006) a restricted roughage, a high-concentrate ration results in significantly lower liver and milk B12 levels and a higher total vitamin B12 activity in serum (Walker \& Elliot 1972). So, the increase of obtained vitamin B12 values is due to the presence of analogues whose presence in considerable quantities interfere with the transport of the vitamin or with metabolic reactions involving in it (Sutton \& Elliot 1972). In agreement with previous researches the vitamin B12 level seems to be linked to pattern of fatty acids in the rumen (Strobel 1992). In dairy cows affected by SARA during early lactation, rumen papilla are not fully developed leading to lower absorption of short chain fatty acids, increased concentration of them within the rumen and decrease of $\mathrm{pH}$ below physiological limits (Kleen et al. 2003). The ruminal wall and its papillae herein play an important role and their development has been described (Dirksen et al. 1984). The ruminal papillae are then of crucial importance in the absorption of short chain fatty acids and their proliferation is promoted by fatty acids arising from the fermentation (Morgante et al. 2007). This suggests that the increase of vitamin B12 was also dependent on propionate and butyrate because when the $\mathrm{pH}$ was below 5.6 ratio between acetic, propionic and butyric acid is shifted towards propionic and butyric acid (Strobel 1992, Hibbard et al. 1995). The suspect that vitamin B12 concentration in blood could decrease in cows affected by SARA because of lysis of bacteria synthesising this vitamin was rejected by our results which confirm that the rumen $\mathrm{pH}$ decrease during SARA, characterised by a transient character, determines minor damages in comparison to acute acidosis. We must also remind that vitamin B12 is stored in the liver $(60 \%)$ and in muscles (30\%) then signs of deficiency are delayed due to relatively high depot reserves, and a possible lack of production by rumen bacteria related to higher demand should be hided by these depots.

Although homocysteine unchanged in dairy cows, its values are significantly decreased in critical and acidosis herds. These modifications are linked to vitamin B12 levels and consequently to the fall of rumen $\mathrm{pH}$. In fact, since homocysteine may undergoes remethylation to methionine in a pathway dependent on vitamin B12 and folate, its decrease results inversely proportional to the increase of vitamin B12 (Welch \& Loscalzo 1998, Finkelstein \& Martin 2000). The decrease reflects also the influence of vitamin deficiencies shown previously on plasma homocysteine levels (Kalkantar-Zadeh et al. 2003, Yeh \& Yeh 2006).

The present data resulted in adequate vitamin B12 and homocysteine levels to meet microbial and cow requirements and fatty acids modifications in dairy cows affected by SARA. These findings may be useful to provide more information on blood modifications during the 
subacute ruminal acidosis in bovine and may be used with advantage in occupational health examinations and in special clinical work. Since we know that consequences from SARA would arise after a certain delay from the initial insult (which make difficult the diagnosis) it is important to prevent the development of disease in critical dairy cows. So, further investigations should be done to assess the relationship between the rumen $\mathrm{pH}$ values, vitamin B12 and homocysteine levels in order to investigate blood levels of these parameters within a fixed period from SARA diagnosis.

\section{References}

Calsamiglia S, Ferret A, Devant M (2002) Effects of $\mathrm{pH}$ and pH fluctuations on microbial fermentation and nutrient flow from a dual-flow continuous culture system. J Dairy Sci 85, 574-579

Chen M, Wolin MJ (1981) Influence of heme and vitamin B12 on growth and fermentations of Bacteroides species. J Bacteriol 145, 466-471

den Heijer M, Koster T, Blom HJ, Gerard MJ, Bos GMJ, Briët E, Reitsma PH (1996) Hyperhomocysteinemia as a risk factor for deep-vein thrombosis. N Engl J Med 334, 759-762

Dirksen G, Liebich HG, Brosi G, Hagemeister H, Mayer E (1984) [Rumen mucosa morphology and fatty acid absorption-significant factors for health and production]. Zbl Vet Med A 31, 414-430 [in German]

Edmonson AJ, Lean IJ, Weaver LD, Farver T, Webster G (1989) A body condition scoring chart for Holstein dairy cows. J Dairy Sci 72, 68-78

Finkelstein JD, Martin JJ (2000) Homocysteine. Int J Biochem Cell Biol 32, 385-389

Gianesella M, Morgante M, Stelletta C, Ravarotto L, Giudice E, Van Saun RJ (2010) Evaluating the Effects of Rumenocentesis on Health and Performance in Dairy Cows. Acta Vet Brno 79, 459-468

Grant RJ, Mertens DR (1992) Influence of buffer $\mathrm{pH}$ and raw corn starch addition on in vitro fiber digestion kinetics. J Dairy Sci 75, 2762-2768

Hibbard B, Peters JP, Chester ST, Robinson JA, Kotarski SF, Croom WJ Jr, Hagler WM Jr (1995) The effect of slaframine on salivary output and subacute and acute acidosis in growing beef steers. J Anim Sci 73, 516525

Kalantar-Zadeh K, Ikizler TA, Block G, Avram MM, Kopple JD (2003) Malnutrition-inflammation complex syndrome in dialysis patients: causes and consequences. Am J Kidney Dis 42, 864-881

Kincaid RL, Socha MT (2007) Effect of Cobalt Supplementation During Late Gestation and Early Lactation on Milk and Serum Measures. J Dairy Sci 90, 1880-1886

Kleen JL, Hooijer GA, Rehage J, Noordhuizen JP (2003) Subacute ruminal acidosis (SARA): a review. J Vet Med A Physiol Pathol Clin Med 50, 406-414

Krajcarski-Hunt H, Plaizier JC, Walton JP, Spratt R, McBride BW (2002) Effect of subacute ruminal acidosis on in situ fiber digestion in lactating dairy cows. J Dairy Sci 85, 570-573

Langman LJ, Ray JG, Evrovski J, Yeo E, Cole DEC (2000) Hyperhomocyst(e)inemia and the increased risk of venous thromboembolism: more evidence from a case-control study. Arch Intern Med 160, 961-964

Morgante M, Stelletta C, Berzaghi P, Gianesella M, Andrighetto I (2007) Subacute rumen acidosis in lactating cows: an investigation in intensive Italian Dairy herds. J Anim Physiol Anim Nutr (Berl) 91, 226-234

Nordlund K (1996) Questions and answers regarding rumenocentesis and the diagnosis of herd-based subacute rumen acidosis. Proc Annu Conf Am Assoc Bovine Pract 75-81

Nordlund K (2001) Herd based diagnosis of subacute ruminal acidosis. Preconvention seminar 8: Dairy herd problem investigations. Am Assoc Bovine Pract 34th Annual Convention, September 11-12, 2001, Vancouver, BC, Canada

Nordlund KV, Garrett EF (1994) Rumenocentesis: a technique for collecting rumen fluid for the diagnosis of subacute rumen acidosis in diary herds. Bovine Practitioner 28, 109-112 
NRC (2001) Nutrient requirements of dairy cattle. 7th rev. ed., National Academies Press, Washington, DC, USA Oetzel GR (2003) Subacute rminal acidosis in dairy cattle. Adv Dairy Tech 15, 307-317

Plaizier JC, Keunen JE, Walton JP, Kyriazakis I, Duffield TF, McBride BW (2001) Effects of subacute ruminal acidosis on in situ digestion of mixed hay in lactating dairy cows. Can J Anim Sci 81, 421-423

Ray JG (1998) Meta-analysis of hyperhomocysteinemia as a risk factor for venous thromboembolic disease. Arch Intern Med 158, 2101-2106

Ridker PM, Hennekens CH, Selhub J, Miletich JP, Malinow MR, Stampfer MJ (1997) Interrelation of hyperhomocyst(e)inemia, factor V Leiden, and risk of future venous thromboembolism. Circulation 95, $1777-1782$

Roblin X, Germain E, Phelip JM, Ducros JM, Pofelski J, Heluwaert F, Oltean P, Faucheron JL, Bonaz B (2005) [Factors associated with hyperhomocysteinemia in inflammatory bowel disease: prospective study in 81 patients] Rev Medlnterne 27, 106-110 [in French]

Romagnuolo J, Fedorak RN, Dias VC, Bamforth F, Teltscher M (2001) Hyperhomocysteinemia and Inflammatory Bowel Disease: Prevalence and Predictors in a Cross-Sectional Study. Am J Gastroenterol, 96, 2143-2149

Schwab EC, Schwab CG, Shaver RD, Girard CL, Putnam DE, Whitehouse NL (2006) Dietary forage and nonfiber carbohydrate contents influence B-vitamin intake, duodenal flow, and apparent ruminal synthesis in lactating dairy cows. J Dairy Sci 89, 174-187

Strobel HJ (1992) Vitamin B12-dependent propionate production by the ruminal bacterium Prevotella ruminicola 23. Appl Environ Microbiol 58, 2331-2333

Sutton AL, Elliot JM (1972) Effect of ratio of roughage to concentrate and level of feed intake on ovine ruminal vitamin B12 production. J Nutr 102, 1341-1346

Tanner RS, Wolfe RS (1988) Nutritional requirements of Methanomicrobium mobile. Appl Environ Microbiol $54,625-628$

Tiffany ME, Fellner V, Spears JW (2006) Influence of cobalt concentration on vitamin B12 production and fermentation of mixed ruminal microorganisms grown in continuous culture flow-through fermentors. J Anim Sci 84, 635-640

Walker CK, Elliot JM (1972) Lactational trends in vitamin B 12 status on conventional and restricted-roughage rations. J Dairy Sci 55, 474-479

Welch GN, Loscalzo J (1998) Homocysteine and atherothrombosis. N Engl J Med 338, 1042-1050

Yeh YY, Yeh SM (2006) Homocysteine-lowering action is another potential cardiovascular protective factor of aged garlic extract. J Nutr (Suppl) 136, 745S-749S

Received 26 August 2011, accepted 29 December 2011.

Corresponding author:

Stefania Casella

email: stefania.casella@unime.it

Dipartimento di Scienze Sperimentali e Biotecnologie Applicate, Facoltà di Medicina Veterinaria, Polo Universitario Annunziata, Messina, 98168, Italy 